\title{
Wild mushrooms and their mycelia as sources of bioactive compounds: Antioxidant, anti-inflammatory and cytotoxic properties
}

\author{
Fedia Souilem ${ }^{\mathrm{a}, \mathrm{b}, \mathrm{c}}$, Ângela Fernandes ${ }^{\mathrm{a}}$, Ricardo C. Calhelha ${ }^{\mathrm{a}}$, João C.M. Barreira ${ }^{\mathrm{a}}$, Lillian Barros ${ }^{\mathrm{a}, \mathrm{b}}$, \\ Fathia Skhiri $^{c}$, Anabela Martins ${ }^{\mathrm{a}, *}$, Isabel C.F.R. Ferreira ${ }^{\mathrm{a}, *}$ \\ a Mountain Research Centre (CIMO), ESA, Polytechnic Institute of Bragança, Campus de Santa Apolónia, 5300-253 Bragança, Portugal \\ ${ }^{\mathrm{b}}$ Laboratory of Separation and Reaction Engineering - Laboratory of Catalysis and Materials (LSRE-LCM), Polytechnic Institute of Bragança, Campus de Santa Apolónia, \\ 5301-857 Bragança, Portugal \\ ${ }^{\mathrm{c}}$ Higher Institute of Biotechnology of Monastir, Université Monastir, Avenue Tahar Haded - B.P. $n^{\circ}$ 74, 5000 Monastir, Tunisia
}

\section{A R T I C L E I N F O}

\section{Article history:}

Received 13 September 2016

Received in revised form 1 March 2017

Accepted 6 March 2017

Available online 7 March 2017

\section{Keywords:}

Pleurotus eryngii

Suillus bellinii

Ergosterol

Phenolic acids

Antioxidant activity

Anti-inflammatory activity

Anti-proliferative activity

\begin{abstract}
A B S T R A C T
Mushrooms are important sources of natural bioactive compounds. Pleurotus eryngii (DC.) Quél is recognized for its organoleptic quality and health effects, being extensively commercialized. Instead, Suillus bellinii (Inzenga) Watling is an ectomycorrhizal symbiont, whose main properties were scarcely reported. Considering current trends, the mycelia and the culture media of these mushrooms might be potential sources of bioactive compounds. Accordingly, P. eryngii and S. bellinii were studied for their phenolic acids and sterols, antioxidant capacity, anti-inflammatory effect and anti-proliferative activity. S. bellinii mycelia showed higher contents of ergosterol and phenolic compounds (also higher in its fruiting body) and stronger antioxidant activity than P. eryngii. Conversely, P. eryngii mycelia showed anti-inflammatory (absent in S. bellinii mycelia) and a cytotoxicity similar (sometimes superior) to its fruiting bodies, contrarily to $S$. bellinii. Furthermore, the assayed species showed differences in the growth rate and produced mycelia, which should be considered in further applications.
\end{abstract}

(c) 2017 Elsevier Ltd. All rights reserved.

\section{Introduction}

Since ancient times, there is a wide interest in using edible mushrooms as functional foods or sources of natural medicine components (Shi, Zhao, Jiao, Shi, \& Yang, 2013).

Pleurotus eryngii is one of the most favored and widely consumed mushroom species, being also called "king oyster mushroom". Besides its organoleptic quality, P. eryngii is acknowledged as a good dietary source of bioactive compounds with reported effects on the reduction of hyperlipidemia (Chen et al., 2012), tumor growth, hepatogenic and atherosclerotic conditions (Chen et al., 2014; Yang et al., 2013). Most of the available reports describe the polysaccharide fraction of $P$. eryngii, which was highlighted as having antioxidant, anti-aging, anti-tumor and hepatoprotective activity (Gan, Ma, Jiang, Wang, \& Zeng, 2012; Jayakumar, Sakthivel, Thomas, \& Geraldine, 2008). Nevertheless, other important bioactive compounds such as polyphenols, peptides, sterols and dietary fiber were also reported in this species

\footnotetext{
* Corresponding authors.

E-mail addresses: amartins@ipb.pt (A. Martins), iferreira@ipb.pt (I.C.F.R. Ferreira).
}

(Chen et al., 2012; Ferreira, Barros, \& Abreu, 2009; Mishra et al., 2013).

The genus Suillus includes several C-demanding species, such as Suillus bellinii (Inzenga) Watling, which are able to produce large amounts of biomass and exudates (Izumi, Elfstrand, \& Fransson, 2013). S. bellinii is an ectomycorrhizal symbiont, which might grow associated with a wide range of plant hosts (Franco \& Castro, 2015). Nevertheless, there are very scarce data on the chemical composition and bioactivity of this mushroom, having been reported only for its organic acids, phenolic acids (Ribeiro et al., 2006), alcohols (Guedes De Pinho et al., 2008) and antimicrobial activity (Dulger, Hacioglu, \& Suerdem, 2006).

Besides the fruiting bodies, the mycelia and the culture media utilized in mushroom cultivation have also been explored as potential sources of bioactive compounds (Ma et al., 2016). The cultured mycelia are becoming a promising alternative as a source of fungal bioactive compounds, mostly due to the shorter incubation time and easier culture conditions (less required space, low probability of contamination and higher production of biomass, when compared to the fruiting bodies) (Gan et al., 2012; Zhang et al., 2016).

Considering the species herein, the fruiting bodies of $P$. eryngii were previously studied for their chemical composition, 
antioxidant and anti-inflammatory activities, after being harvested at different periods (Barreira, Oliveira, \& Ferreira, 2014; Lin et al., 2014; Reis, Barros, Sousa, Martins, \& Ferreira, 2014; Reis, Martins, Barros, \& Ferreira, 2012). However, as far as we know, the antiinflammatory activity of $S$. bellinii was not reported yet. In addition, the culture media and mycelia of both species were never studied regarding the anti-tumoral and anti-inflammatory activities. Accordingly, their composition in phenolic acids and sterols, antioxidant capacity (scavenging DPPH radicals, reducing power, $\beta$-carotene bleaching inhibition and TBARS formation inhibition), as well as their anti-proliferative activity (using MCF-7, $\mathrm{NCI}-\mathrm{H} 460$, HeLa and HepG2 cell lines) and anti-inflammatory effect (by down-regulating LPS-stimulated NO in RAW264.7 cells) were evaluated.

With this study it was mainly intended to evaluate the effects of different culture conditions on the phenolic acids and ergosterol profiles and in the bioactivity of both species, to fully characterize their potential use in food or pharmaceutical applications.

\section{Materials and methods}

\subsection{Wild samples and in vitro production of mycelia}

Two species of wild mushrooms, Pleurotus eryngii (DC.) Quél and Suillus belinii (Inzenga) Watling, were collected in Bragança (Northeast Portugal) during November 2015. Mycelium was isolated from sporocarps of each sample on different solid: i) potato dextrose agar medium (PDA) (Biolab); ii) Melin-Norkans incomplete medium (without micronutrients, casaminoacids and malt extract) (iMMN solid), and liquid: i) potato dextrose broth (PDB); ii) Melin-Norkans incomplete (without micronutrients, casaminoacids and malt extract) (iMMN liquid) culture media (Marx, 1969).

Mycelia were grown in Petri dishes with $10 \mathrm{~mL}$ of solid media and flasks with $20 \mathrm{~mL}$ of liquid media. Petri dishes and flasks were placed at $22{ }^{\circ} \mathrm{C}$ in the dark until mycelium covered most of the medium: 21 days for $P$. eryngii and 42 days for S. bellinii, approximately. Radial growth measurements were registered every week from the inoculation time until the full growth of the mycelium (covering all available area). The mycelia were further recovered from the medium.

Fruiting bodies, mycelia and culture media were lyophilized (FreeZone 4.5, Labconco, MO, USA) and ground to a fine powder (20 mesh) and weighted to obtain the dry biomass (dw).

\subsection{Standards and reagents}

Acetonitrile and methanol of high-performance liquid chromatography (HPLC) grade were obtained from Lab-Scan (Lisbon, Portugal). Trolox (6-hydroxy-2,5,7,8- tetramethylchroman2-carboxylic acid), ergosterol and phenolic acids standards, sulforhodamine B, trypan blue, trichloroacetic acid (TCA), tris lipopolysaccharide (LPS) and dexamethasone were purchased from Sigma (St. Louis, MO, USA). 2,2-Diphenyl-1-picrylhydrazyl (DPPH) was obtained from Alfa Aesar (Ward Hill, MA, USA). Dulbecco's modified Eagle's medium (HyClone), Hank's balanced salt solution (HBSS) and all the additional culture media components were purchased from Gibco Invitrogen Life Technologies (Paisley, UK). RAW264.7 cells were acquired from ECACC ("European Collection of Animal Cell Culture") (Salisburg, UK), Griess reagent system kit was purchased from Promega, thiamine, casamino acids, malt extract and agar were obtained from Panreac Applichem (Barcelona, Spain). The microbial culture media were acquired from Oxoid microbiology products (Hampshire, United Kingdom). Other reagents and solvents (analytical grade) were obtained from common sources. Water was treated in a Milli-Q water purification system (TGI Pure Water Systems, Greenville, SC, USA).

\subsection{Preparation of the extracts}

The extraction was carried out by stirring the samples $(\approx 2 \mathrm{~g})$ with methanol $(30 \mathrm{~mL})$ at $25^{\circ} \mathrm{C}$ and $150 \mathrm{rpm}$, for $1 \mathrm{~h}$. The extract was separated from the residue by filtration through Whatman No. 4 paper to a round flask. The residue was re-extracted once more under the same conditions and the filtrates were combined and concentrated under vacuum (rotary evaporator, Büchi, Flawil, Switzerland) (Reis et al., 2012).

\subsection{Chemical characterization of the extracts}

\subsubsection{Analysis of phenolic acids}

The purified extracts were prepared in methanol $(20 \mathrm{mg} / \mathrm{mL})$, filtered through a $0.22 \mu \mathrm{m}$ nylon syringe filter and further analyzed by ultra-fast liquid chromatography (UFLC) using a Shimadzu 20A series (Shimadzu Cooperation, Kyoto, Japan) (Reis et al., 2012). The quantification ( $\mu \mathrm{g} / \mathrm{g}$ of extract) was made by comparing the area of chromatographic peaks ( 280 and $320 \mathrm{~nm}$ ) with the calibration curves $(5-100 \mu \mathrm{g} / \mathrm{mL})$ of the corresponding commercial standards: protocatechuic acid ( $\left.\mathrm{y}=164741 \mathrm{x}, R^{2}=0.9996\right)$, $p$-hydroxybenzoic acid $\left(\mathrm{y}=113523 \mathrm{x}, R^{2}=0.9993\right), p$-coumaric acid $(\mathrm{y}=433521 \mathrm{x}$, $\left.R^{2}=0.9981\right)$ and cinnamic acid $\left(\mathrm{y}=583527 \mathrm{x}, R^{2}=0.9961\right)$, 5$80 \mu \mathrm{g} / \mathrm{mL}$

\subsubsection{Analysis of ergosterol}

The sterol extracts were dissolved in methanol $(20 \mathrm{mg} / \mathrm{mL})$, filtered through a $0.22 \mu \mathrm{m}$ nylon syringe filter and characterized by high performance liquid chromatography coupled to an ultraviolet detector (HPLC-UV) (Barreira et al., 2014). Chromatographic data (obtained at $285 \mathrm{~nm}$ ) were analyzed using Clarity 2.4 Software (DataApex, Podohradska, Czech Republic). Ergosterol was quantified $(\mathrm{mg} / \mathrm{g}$ of extract) using the internal standard (cholecalciferol) method.

\subsection{Evaluation of bioactive properties}

\subsubsection{Antioxidant activity}

The final extracts were dissolved in methanol at appropriate concentrations $(10-80 \mathrm{mg} / \mathrm{mL})$ and several dilutions were obtained from the stock solutions: $0.005-50 \mathrm{mg} / \mathrm{mL}$, depending on the assay.

The sample concentrations providing $50 \%$ of antioxidant activity or 0.5 of absorbance $\left(\mathrm{EC}_{50}\right)$ were calculated from the graphs of antioxidant activity percentages (DPPH, $\beta$-carotene/linoleate and TBARS assays) or absorbance at $690 \mathrm{~nm}$ (reducing power assay) against sample concentrations (Heleno, Barros, Sousa, Martins, \& Ferreira, 2010). Trolox was used as standard.

\subsubsection{Antioxidant activity}

DPPH radical scavenging activity. This methodology was performed using an ELX800 Microplate Reader (Bio-Tek). The reaction mixture in each one of the 96-wells consisted of one of the different concentrations of the extracts $(30 \mu \mathrm{L})$ and methanolic solution $(270 \mu \mathrm{L})$ containing $\mathrm{DPPH}$ radicals $\left(6 \times 10^{-5} \mathrm{~mol} / \mathrm{L}\right)$. The mixture was left to stand for $60 \mathrm{~min}$ in the dark. The reduction of the DPPH radical was determined by measuring the absorption at $515 \mathrm{~nm}$. The radical scavenging activity (RSA) was calculated as a percentage of DPPH discoloration using the equation: \% RSA = $\left[\left(A_{D P P H}-A_{S}\right) / A_{D P P H}\right] \times 100$, where $A_{S}$ is the absorbance of the solution when the sample extract has been added at a particular level and $A_{D P P H}$ is the absorbance of the DPPH solution. 
Reducing power. Was performed using the Microplate Reader described above. The different concentrations of the extracts $(0.5 \mathrm{~mL})$ were mixed with sodium phosphate buffer $(200 \mathrm{mmol} / \mathrm{L}$, $\mathrm{pH} 6.6,0.5 \mathrm{~mL})$ and potassium ferricyanide $(1 \% \mathrm{w} / \mathrm{v}, 0.5 \mathrm{~mL})$. For each concentration, the mixture was incubated at $50{ }^{\circ} \mathrm{C}$ for $20 \mathrm{~min}$, and trichloroacetic acid $(10 \% \mathrm{w} / \mathrm{v}, 0.5 \mathrm{~mL})$ was added. The mixture $(0.8 \mathrm{~mL})$ was poured in the 48 -wells, as also deionized water $(0.8 \mathrm{~mL})$ and ferric chloride $(0.1 \% \mathrm{w} / \mathrm{v}, 0.16 \mathrm{~mL})$, and the absorbance was measured at $690 \mathrm{~nm}$.

Inhibition of $\beta$-carotene bleaching. $\beta$-carotene $(2 \mathrm{mg})$ was dissolved in chloroform $(10 \mathrm{~mL})$ and $2 \mathrm{~mL}$ of this solution were pipetted into a round-bottom flask. After the chloroform was removed at $40{ }^{\circ} \mathrm{C}$ under vacuum, linoleic acid (40 mg), Tween 80 emulsifier $(400 \mathrm{mg})$, and distilled water $(100 \mathrm{~mL})$ were added to the flask with vigorous shaking. Aliquots $(4.8 \mathrm{~mL})$ of this emulsion were transferred into different test tubes containing different concentrations of the extracts $(0.2 \mathrm{~mL})$. The tubes were shaken and incubated at $50{ }^{\circ} \mathrm{C}$ in a water bath. As soon as the emulsion was added to each tube, the zero time absorbance was measured at $470 \mathrm{~nm}$. $\beta$-Carotene bleaching inhibition was calculated using the following equation: (absorbance after $2 \mathrm{~h}$ of assay/initial absorbance) $\times 100$.

TBARS (thiobarbituric acid reactive substances) assay. Porcine brains were obtained from official slaughtered animals, dissected, and homogenized with a Polytron in ice cold Tris- $\mathrm{HCl}$ buffer (20 mM, pH 7.4) to produce a $1: 2 \mathrm{w} / \mathrm{v}$ brain tissue homogenate which was centrifuged at $3000 \mathrm{~g}$ for $10 \mathrm{~min}$. An aliquot $(100 \mu \mathrm{L})$ of the supernatant was incubated with the different concentrations of the samples solutions $(200 \mu \mathrm{L})$ in the presence of $\mathrm{FeSO}_{4}(10 \mathrm{mM}$; $100 \mu \mathrm{L})$ and ascorbic acid $(0.1 \mathrm{mM} ; 100 \mu \mathrm{L})$ at $37^{\circ} \mathrm{C}$ for $1 \mathrm{~h}$. The reaction was stopped by the addition of trichloroacetic acid (28\% $\mathrm{w} / \mathrm{v}, 500 \mu \mathrm{L}$ ), followed by thiobarbituric acid (TBA, 2\%, w/v, $380 \mu \mathrm{L}$ ), and the mixture was then heated at $80^{\circ} \mathrm{C}$ for $20 \mathrm{~min}$. After centrifugation at $3000 \mathrm{~g}$ for $10 \mathrm{~min}$ to remove the precipitated protein, the color intensity of the malondialdehyde (MDA)-TBA complex in the supernatant was measured by its absorbance at $532 \mathrm{~nm}$. The inhibition ratio (\%) was calculated using the following formula: Inhibition ratio $(\%)=[(A-B) / A] \times 100 \%$, where $A$ and $B$ were the absorbance of the control and the sample solution, respectively.

\subsubsection{Anti-inflammatory activity}

Cells treatment. For the anti-inflammatory activity assay, the methanolic extracts were dissolved in water at a concentrated of $8 \mathrm{mg} / \mathrm{mL}$. For the various assays, the extracts were then submitted to further dilutions from $0.4 \mathrm{mg} / \mathrm{mL}$ to $0.005 \mathrm{mg} / \mathrm{mL}$. The mouse macrophage-like cell line RAW 264.7 was cultured in DMEM medium supplemented with $10 \%$ heat-inactivated foetal bovine serum, glutamine and antibiotics at $37{ }^{\circ} \mathrm{C}$ under $5 \% \mathrm{CO}_{2}$, in humidified air. For each experiment, cells were detached with a cell scraper. In the experiment cell density of $5 \times 10^{5}$ cells/mL was used, and the proportion of dead cells was less than $5 \%$ according to the Trypan blue dye exclusion test. Cells were seeded in 96-well plates at 150,000 cells/well and allowed do attach to the plate overnight. Subsequently, cells were treated with the various concentrations of each extract for $1 \mathrm{~h}$. Dexamethasone $(50 \mu \mathrm{M})$ was used as a positive control for the experiment. The following step was the stimulation with LPS $(1 \mu \mathrm{g} / \mathrm{mL})$ for $18 \mathrm{~h}$. The effect of all the tested samples in the absence of LPS was also evaluated, in order to observe if they induced changes in Nitric oxide (NO) basal levels. In negative controls, no LPS was added. Both extracts and LPS were dissolved in supplemented DMEM (Souza et al., 2015).

Nitric oxide determination. For the determination of nitric oxide, a Griess Reagent System kit was used, which contains sulphanilamide, N-(1-napthyl)ethylenediamine hydrochloride (NED) and nitrite solutions. A reference curve of nitrite (sodium nitrite
$100 \mu \mathrm{M}$ to $\left.1.6 \mu \mathrm{M} ; \mathrm{y}=0.0066 \mathrm{x}+0.1349 ; R^{2}=0.9986\right)$ was prepared in a 96 -well plate. The cell culture supernatant $(100 \mu \mathrm{L})$ was transferred to the plate and mixed with sulphanilamide and NED solutions, 5-10 min each, at room temperature. The nitric oxide produced was determined by measuring the absorbance at $540 \mathrm{~nm}$ (microplate reader ELX800 Biotek), and by comparison with the standard calibration curve (Souza et al., 2015). The results were expressed in $\mathrm{EC}_{50}$ values $(\mu \mathrm{g} / \mathrm{mL})$, which correspond to the sample concentration providing $50 \%$ of inhibition of nitric oxide (NO) production.

\subsubsection{Cytotoxic activity}

The final extracts were dissolved in water at $8 \mathrm{mg} / \mathrm{mL}$ and several dilutions were obtained from the stock solutions: $0.125-0.4 \mathrm{mg} / \mathrm{mL}$. Ellipticine was used as positive control.

2.5.4.1. In human tumor cell lines. MCF-7 (breast adenocarcinoma), NCI-H460 (non-small cell lung carcinoma), HeLa (cervical carcinoma) and HepG2 (hepatocellular carcinoma) were used as human tumor cell lines and the cell density determination was performed using a sulforhodamine B assay previously described by Guimarães et al. (2013). RPMI-1640 medium containing 10\% heat-inactivated FBS and $2 \mathrm{mM}$ glutamine was used to routinely maintain the adherent cell cultures at $37^{\circ} \mathrm{C}$, in a humidified air incubator containing 5\% CO2. For the experiments, each cell line was placed at an appropriate density $(1.0 \times 104$ cells/well $)$ into 96 -well plates. A procedure using the sulforhodamine $\mathrm{B}$ assay was performed. The extract concentration that inhibited $50 \%$ of the net cell growth $\left(\mathrm{GI}_{50}\right)$ was calculated from the graph of sample concentration against percentage of growth inhibition and expressed in $\mu \mathrm{g} / \mathrm{mL}$ extract.

2.5.4.2. In non-tumor cells. The effect of the extracts on the growth of porcine liver primary cells (PLP2), established by the group, was evaluated by the sulforhodamine B colorimetric assay with some modifications as described by Abreu et al. (2011). Briefly, the liver tissue was rinsed in Hank's balanced salt solution containing $100 \mathrm{U} / \mathrm{mL}$ penicillin $+100 \mu \mathrm{g} / \mathrm{mL}$ streptomycin, and was divided into $1 \times 1 \mathrm{~mm}^{3}$ explants. Some of them were placed into $25 \mathrm{~cm}^{2}$ tissue flasks containing DMEM medium (supplemented with 10\% fetal bovine serum, $2 \mathrm{mM}$ non-essential amino acids and $100 \mathrm{U} /$ $\mathrm{mL}$ penicillin, $100 \mathrm{mg} / \mathrm{mL}$ streptomycin) and incubated at $37^{\circ} \mathrm{C}$ under a humidified atmosphere with $5 \% \mathrm{CO}_{2}$. Phase contrast microscope was used for direct monitoring of the cell cultivation every 2-3 days. Before reaching the confluence, cells were subcultured and plated in 96-well plates at a density of $1.0 \times 10^{4}$ cells/well, and cultivated in commercial DMEM medium supplemented with $10 \%$ FBS, $100 \mathrm{U} / \mathrm{mL}$ penicillin and $100 \mu \mathrm{g} / \mathrm{mL}$ streptomycin. The results were expressed as $\mathrm{GI}_{50}$ values (sample concentration that inhibited $50 \%$ of the net cell growth) in $\mu \mathrm{g} / \mathrm{mL}$ extract.

\subsection{Statistical analysis}

Three independent samples of each culture component, fruiting body and fungal species were used. Data were expressed as mean \pm standard deviation. All statistical tests were performed at a $5 \%$ significance level using IBM SPSS Statistics for Windows, version 22.0. (IBM Corp., USA).

The results were compared through one-way ANOVA after checking the normal distribution of the residuals (Shapiro Wilk's test) and the homogeneity of variance (Levene's test). The dependent variables were classified using multiple comparison tests (Tukey's honestly significant difference (HSD) for homoscedastic distributions and Tamhane's T2 for the heteroscedastic ones). 


\section{Results and discussion}

Edible mushrooms, in general, are esteemed primarily for their nutritional value and bioactive properties mostly provided by different active substances, such as polysaccharides, lipids, peptides, sterols, or fiber (Ren, Wang, Guo, Yuan, \& Yang, 2016). The great majority of the studies reporting the previous features are conducted on the fruiting body, but the mycelia, as well as the culture media utilized in different stages of mushroom production, might also represent a good source of valuable compounds.

Besides the differences in bioactive compounds and corresponding activities, the growth rate and yielded biomass of mycelia are of paramount importance, since these parameters might define the industrial interest of each species. Accordingly, both indicators are presented in Figs. 1 and 2 to allow a proper assessment of their true applicability. As it can be seen, $P$. eryngii presented a higher growth rate, despite the similarities in the produced biomass (except for the mycelia grown in PDB).

In the following sections, the mycelia and culture media are compared by evaluating different bioactive compounds and biolog- ical activity indicators. In all tables, results corresponding to wild samples of each studied species are also presented as reference values.

\subsection{Chemical characterization of the extracts}

The phenolic acids profile and ergosterol contents are presented in Table 1. In general, the fruiting body presented higher contents in phenolic acids (Fig. 3), but it was very interesting to find that the mycelium of $S$. bellinii (independently of the culture conditions) gave higher contents (8.9-12.4 mg/g extract) in ergosterol (Fig. 3) than the corresponding wild samples $(6.5 \mathrm{mg} / \mathrm{g}$ extract). There are limited data on the sterols content of $S$. bellinii, but it was reported as having $12 \mathrm{mg} / 100 \mathrm{~g}$ fw ergosterol (Kalogeropoulos, Yanni, Koutrotsios, \& Aloupi, 2013), which is higher than the values reported in the present work.

$P$. eryngii gave lower contents in ergosterol, either considering the mycelia $(0.10-1.0 \mathrm{mg} / \mathrm{g}$ extract), as well as the fruiting body ( $4.1 \mathrm{mg} / \mathrm{g}$ extract), when compared to $S$. bellinii. The ergosterol content in P. eryngii was previously reported as $20 \mathrm{mg} / 100 \mathrm{~g} \mathrm{dw}$

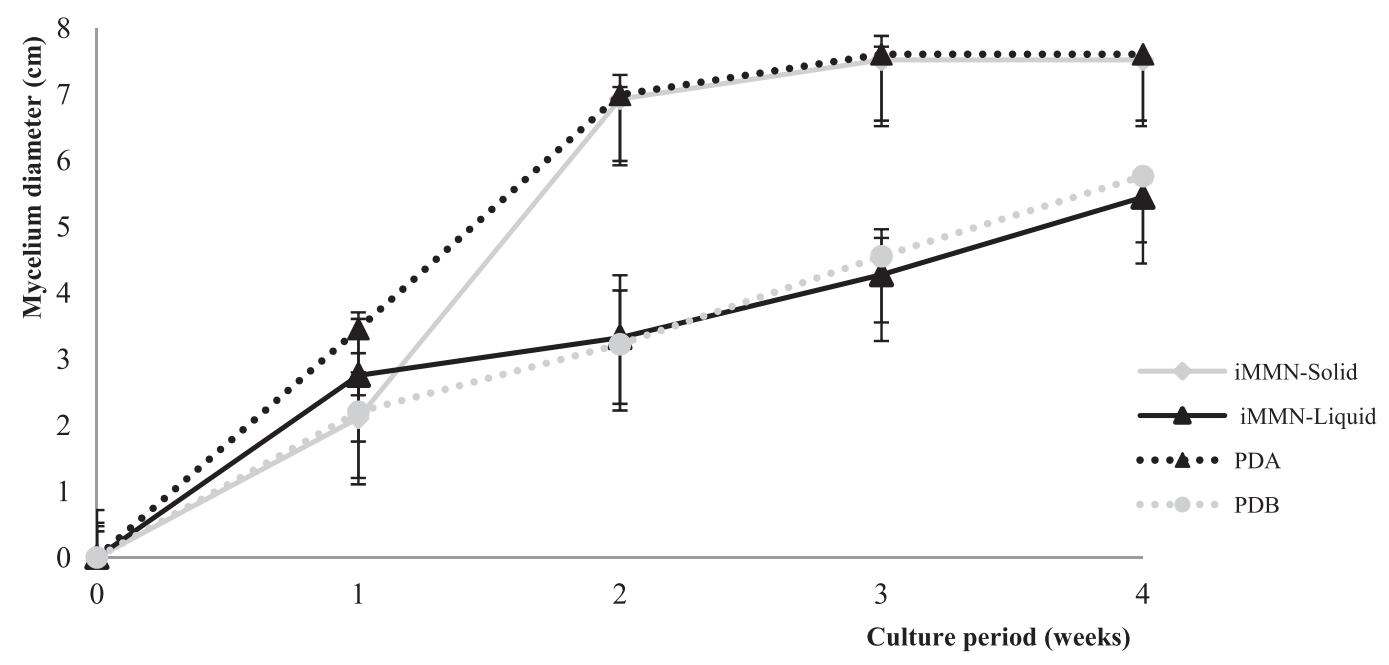

(A)

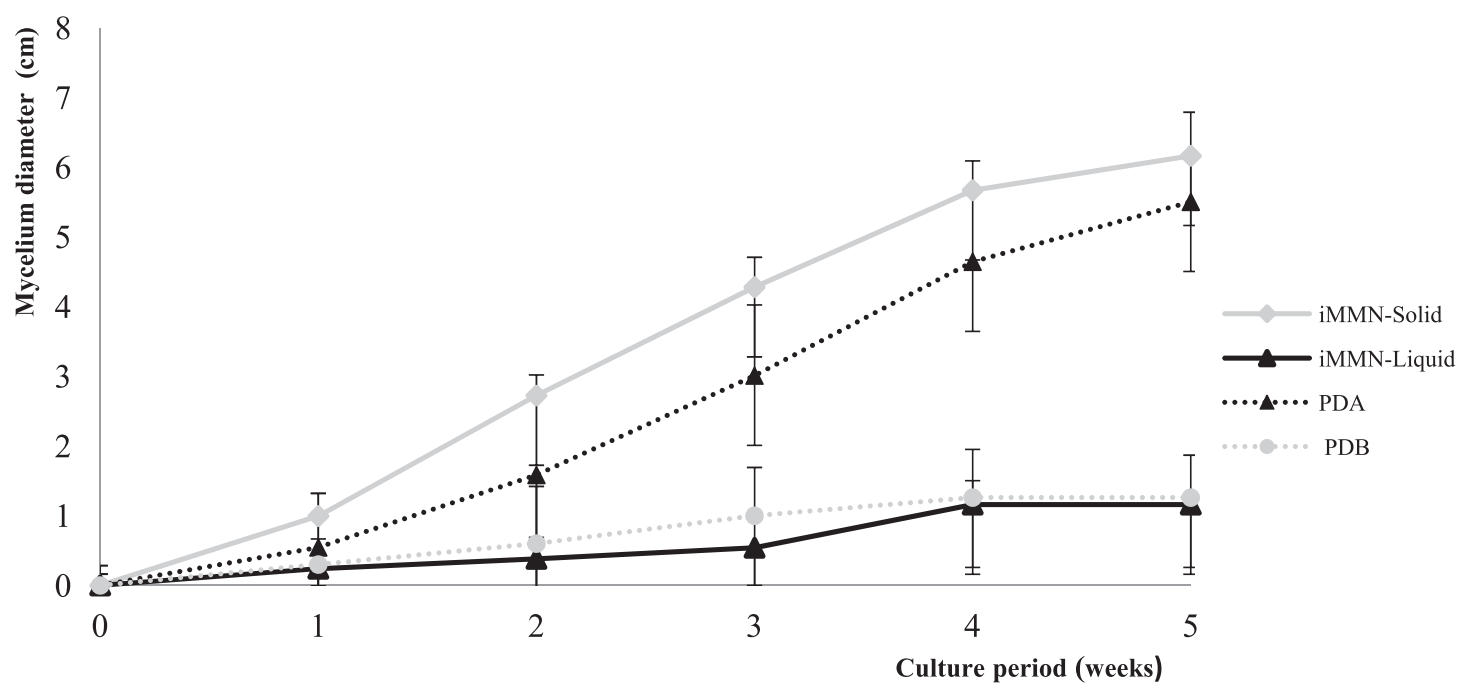

(B)

Fig. 1. Growth in diameter of the mycelia of P. eryngii (A) and S. bellinii (B) cultivated in different culture media throughout time. 


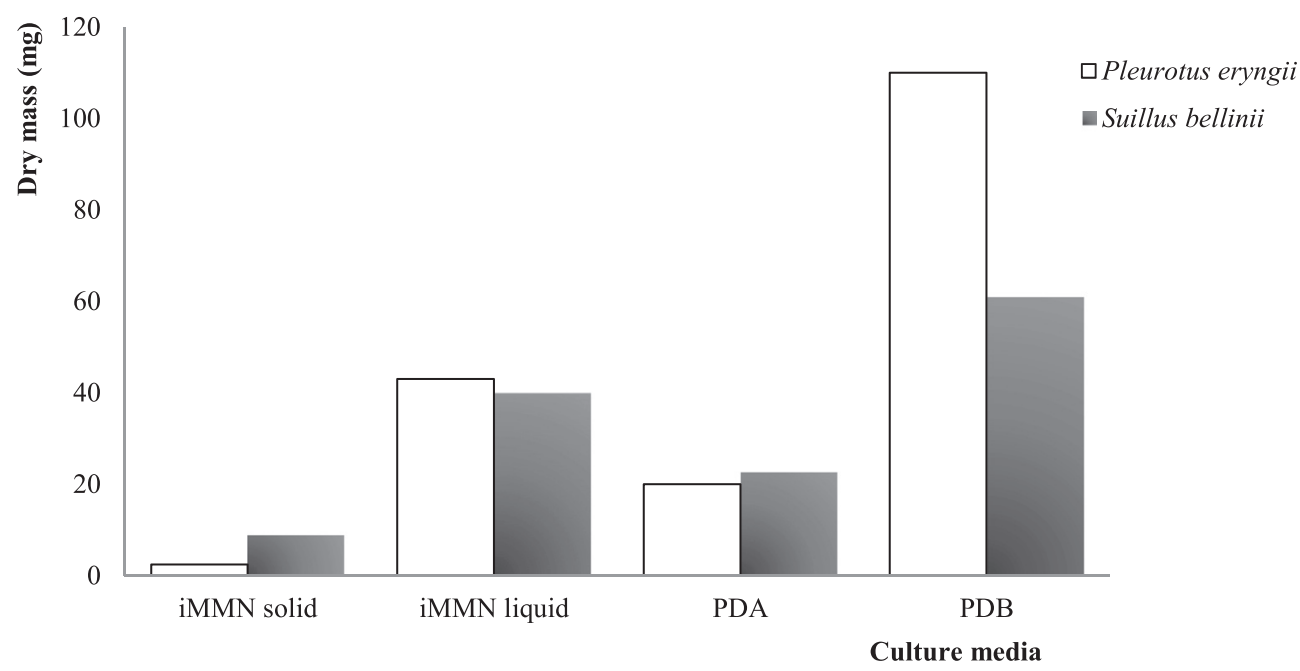

Fig. 2. Average biomass of P. eryngii and S. bellinii mycelia (mg/Petri dish or Flask).

Table 1

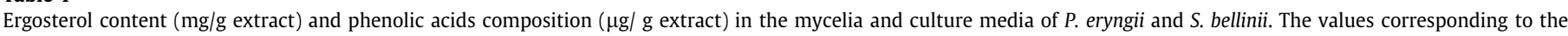
fruiting body of both mushrooms (wild samples) are also presented. Values are given as mean \pm standard deviation.

\begin{tabular}{|c|c|c|c|c|c|c|}
\hline & & Ergosterol & Protocatechuic acid & p-Hydroxybenzoic acid & $p$-Coumaric acid & Cinnamic acid \\
\hline \multicolumn{7}{|l|}{ Pleurotus eryngii } \\
\hline Fruiting body (wild) & & $4.1 \pm 0.3$ & nd & $273 \pm 10$ & $42 \pm 4$ & $61 \pm 4$ \\
\hline \multirow[t]{2}{*}{ iMMN liquid } & Mycelium & $0.6 \pm 0.1^{b}$ & nd & $186 \pm 8^{\mathrm{a}}$ & nd & $34 \pm 3^{b}$ \\
\hline & Culture medium & nd & nd & nd & nd & nd \\
\hline \multirow[t]{2}{*}{ PDB } & Mycelium & $0.10 \pm 0.02^{c}$ & nd & $122 \pm 6^{\mathrm{c}}$ & nd & $49 \pm 4^{\mathrm{a}}$ \\
\hline & Culture medium & nd & nd & nd & nd & nd \\
\hline iMMN solid & Mycelium & $0.9 \pm 0.1^{\mathrm{a}}$ & nd & $149 \pm 9^{b}$ & nd & $15 \pm 2^{\mathrm{c}}$ \\
\hline PDA & Mycelium & $1.0 \pm 0.1^{\mathrm{a}}$ & nd & $178 \pm 8^{\mathrm{a}}$ & nd & $15 \pm 2^{c}$ \\
\hline \multirow[t]{2}{*}{$p$-values $(n=54)$} & Homoscedasticity $^{1}$ & $<0.001$ & - & $<0.001$ & - & $<0.001$ \\
\hline & 1-way ANOVA ${ }^{2}$ & $<0.001$ & - & $<0.001$ & - & $<0.001$ \\
\hline \multicolumn{7}{|l|}{ Suillus bellinii } \\
\hline Fruiting body (wild) & & $6.5 \pm 0.4$ & $403 \pm 16$ & $1821 \pm 97$ & nd & $39 \pm 4$ \\
\hline \multirow[t]{2}{*}{ iMMN Liquid } & Mycelium & $8.9 \pm 0.5^{b}$ & nd & $213 \pm 7^{c}$ & nd & $130 \pm 1^{\mathrm{a}}$ \\
\hline & Culture medium & nd & nd & nd & nd & nd \\
\hline \multirow[t]{2}{*}{ PDB } & Mycelium & $12.4 \pm 0.5^{\mathrm{a}}$ & nd & $204 \pm 11^{\mathrm{c}}$ & nd & $111 \pm 4^{\mathrm{b}}$ \\
\hline & Culture medium & nd & nd & nd & nd & nd \\
\hline iMMN solid & Mycelium & $9.0 \pm 0.4^{b}$ & nd & $394 \pm 15^{\mathrm{a}}$ & nd & $25 \pm 2^{d}$ \\
\hline PDA & Mycelium & $3.5 \pm 0.3^{c}$ & nd & $372 \pm 16^{\mathrm{b}}$ & nd & $36 \pm 3^{c}$ \\
\hline \multirow[t]{2}{*}{$p$-value $(\mathrm{n}=54)$} & Homoscedasticity $^{1}$ & $<0.001$ & - & $<0.001$ & - & $<0.001$ \\
\hline & 1-way ANOVA ${ }^{2}$ & $<0.001$ & - & $<0.001$ & - & $<0.001$ \\
\hline
\end{tabular}

\footnotetext{
1 Homoscedasticity among culture components was tested by the Levene test: homoscedasticity, $p>0.05$; heteroscedasticity, $p<0.05$.

$2 p<0.05$ indicates that the mean value of at least one component differs from the others (in this case, multiple comparison tests were performed). For each culture component, means within a column with different letters differ significantly $(p<0.05)$.
}

(Barreira et al., 2014), but that higher value was measured in commercial samples, which might justify the difference in comparison to the result reported here.

Among the phenolic acids, $p$-hydroxybenzoic acid was the major compound in both mushrooms, reaching quantities nearly sevenfold higher in $S$. bellinii $(1821 \mu \mathrm{g} / \mathrm{g}$ extract). Nevertheless, the main phenolic acid in $S$. bellinii was previously reported as being $p$-hydroxyphenylacetic acid $(45 \mu \mathrm{g} / 100 \mathrm{~g}$ fresh weight), among $p$-hydroxybenzoic acid derivatives, and o-coumaric acid $(15 \mu \mathrm{g} / 100 \mathrm{~g}$ fresh weight), in what concerns hydroxycinnamic acids. In the same study, the concentration of $p$-hydroxybenzoic was $7 \mu \mathrm{g} / 100 \mathrm{~g}$ fresh weight (Kalogeropoulos et al., 2013), which is in the range of the concentrations detected herein, considering typical moisture contents $(\approx 90 \%)$ and extraction yields $(\approx 5 \%)$ for this particular mushroom species.

Concerning $P$. eryngii, the phenolic acids profile is in agreement with previous works conducted with samples from the same geographic area, but different harvesting years (Ferreira et al., 2009;
Heleno, Martins, Queiroz, \& Ferreira, 2015; Reis et al., 2014). Even so, in a similar study, syringic acid and vanillic acid were reported in quantities similar to $p$-hydroxybenzoic acid (Lin et al., 2014).

\subsection{Antioxidant activity}

The results obtained for each of the performed antioxidant activity assays, given as $\mathrm{EC}_{50}$ values, are shown in Table 2 . In all evaluated cases, the highest activity was obtained on the TBARS formation inhibition assay ( $P$. eryngii: $0.11 \mathrm{mg} / \mathrm{mL}$ extract; S. bellinii: $0.011 \mathrm{mg} / \mathrm{mL}$ extract), followed by $\beta$-carotene bleaching inhibition (P. eryngii: $0.45 \mathrm{mg} / \mathrm{mL}$ extract; $S$. bellinii: $0.12 \mathrm{mg} / \mathrm{mL}$ extract), reducing power ( $P$. eryngii: $0.98 \mathrm{mg} / \mathrm{mL}$ extract; $S$. bellinii: $0.16 \mathrm{mg} / \mathrm{mL}$ extract) and scavenging effects on DPPH radicals (P. eryngii: $12.8 \mathrm{mg} / \mathrm{mL}$ extract; $S$. bellinii: $0.61 \mathrm{mg} / \mathrm{mL}$ extract). In line with its higher quantities of phenolic acids, the fruiting bodies of $S$. bellinii showed higher antioxidant activity than $P$. eryngii, sometimes 10 -fold or 20 -fold higher, such as verified in the TBARS 

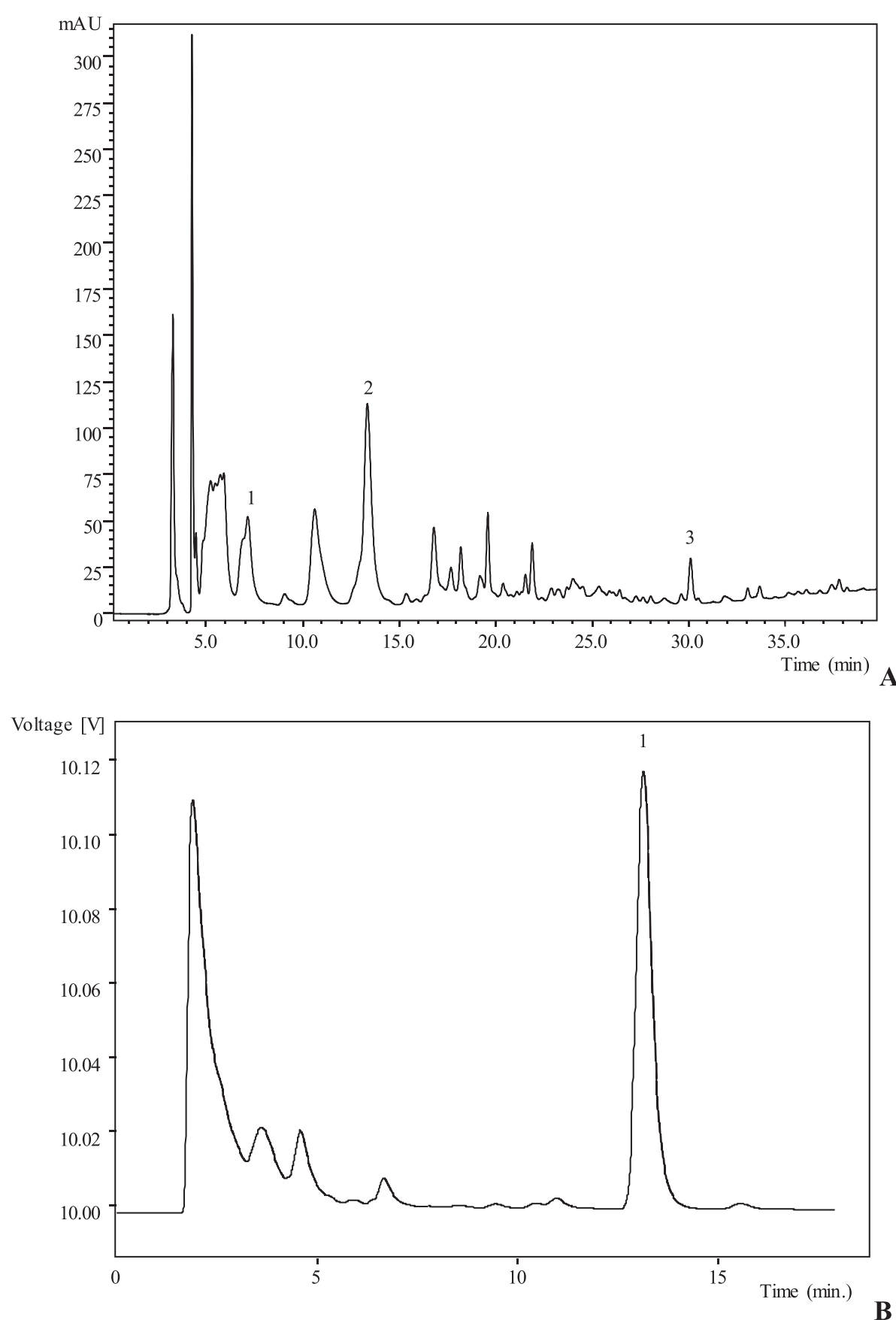

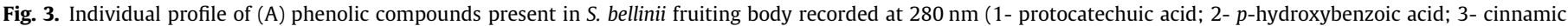
acid) and (B) ergosterol present in S. bellinii mycelium grown on PDB (1- ergosterol).

formation inhibition and DPPH scavenging activity, respectively. Nevertheless, the values obtained for $P$. eryngii represent higher antioxidant activity (except for the DPPH scavenging activity assay) than that reported previously (Lin et al., 2014; Reis et al., 2012).

Regarding S. bellinii, an activity of $35 \%$ in DPPH scavenging activity, at $0.15 \mathrm{mg} / \mathrm{mL}$ was previously reported (Ribeiro et al., 2006), which is slightly better than the $50 \%$ activity obtained in this study for the $0.61 \mathrm{mg} / \mathrm{mL}$ concentration. In a similar study, performed with Greek samples of $S$. bellinii, this mushroom also showed high radical scavenging activity and reducing power, but the results are not directly comparable, because they were given in trolox equivalents (Kalogeropoulos et al., 2013).
Considering the main purpose of this work, it was very interesting to discover that the antioxidant activity measured in the mycelia and in the culture media was very close (in some cases better) to that verified in the fruiting bodies, emphasizing the high potential of these fungal culture components. In the case of the culture media, these results have an increased interest, since those components are usually considered as by-products of mushroom cultivation. Furthermore, the differences among the same culture media, after having been used to grow each of the mushrooms, indicate that the measured antioxidant activity is in fact due to the mycelium, and not to the culture media components. Furthermore, some compounds responsible for the antioxidant activity are not 
Table 2

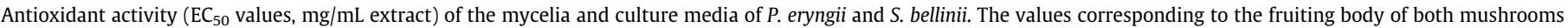
(wild samples) are also presented. Values are given as mean \pm standard deviation.

\begin{tabular}{|c|c|c|c|c|c|}
\hline & & DPPH scavenging activity & Reducing power & $\beta$-carotene bleaching inhibition & TBARS formation inhibition \\
\hline \multicolumn{6}{|l|}{ Pleurotus eryngii } \\
\hline Fruiting body (wild) & & $12.8 \pm 0.2$ & $0.98 \pm 0.01$ & $0.45 \pm 0.02$ & $0.11 \pm 0.01$ \\
\hline \multirow[t]{2}{*}{ iMMN liquid } & Mycelium & $24.9 \pm 0.3^{b}$ & $1.35 \pm 0.02^{\mathrm{a}}$ & $0.44 \pm 0.03^{\mathrm{c}}$ & $0.17 \pm 0.01^{\mathrm{b}}$ \\
\hline & Culture medium & $28.2 \pm 0.5^{\mathrm{a}}$ & $1.24 \pm 0.05^{\mathrm{b}}$ & $0.57 \pm 0.01^{\mathrm{a}}$ & $0.20 \pm 0.02^{\mathrm{a}}$ \\
\hline \multirow[t]{2}{*}{ PDB } & Mycelium & $19.7 \pm 0.5^{\mathrm{d}}$ & $1.10 \pm 0.01^{\mathrm{c}}$ & $0.40 \pm 0.05^{\mathrm{c}}$ & $0.15 \pm 0.01^{c}$ \\
\hline & Culture medium & $22.0 \pm 0.5^{c}$ & $0.95 \pm 0.02^{\mathrm{e}}$ & $0.52 \pm 0.02^{\mathrm{b}}$ & $0.17 \pm 0.01^{\mathrm{b}}$ \\
\hline iMMN solid & Mycelium & $17.1 \pm 0.5^{\mathrm{e}}$ & $1.08 \pm 0.01^{\mathrm{c}}$ & $0.23 \pm 0.01^{\mathrm{d}}$ & $0.13 \pm 0.01^{\mathrm{d}}$ \\
\hline PDA & Mycelium & $16.1 \pm 0.5^{f}$ & $1.03 \pm 0.01^{\mathrm{d}}$ & $0.18 \pm 0.02^{\mathrm{e}}$ & $0.11 \pm 0.01^{\mathrm{e}}$ \\
\hline \multirow[t]{2}{*}{$p$-value $(\mathrm{n}=54)$} & Homoscedasticity $^{1}$ & 0.015 & $<0.001$ & $<0.001$ & $<0.001$ \\
\hline & 1-way ANOVA ${ }^{2}$ & $<0.001$ & $<0.001$ & $<0.001$ & $<0.001$ \\
\hline \multicolumn{6}{|l|}{ Suillus bellinii } \\
\hline Fruiting body (wild) & & $0.61 \pm 0.01$ & $0.16 \pm 0.01$ & $0.12 \pm 0.01$ & $0.011 \pm 0.001$ \\
\hline \multirow[t]{2}{*}{ iMMN liquid } & Mycelium & $1.10 \pm 0.01^{\mathrm{b}}$ & $0.84 \pm 0.02^{\mathrm{b}}$ & $0.21 \pm 0.03^{\mathrm{b}}$ & $0.14 \pm 0.01^{\mathrm{a}}$ \\
\hline & Culture medium & $1.18 \pm 0.02^{\mathrm{a}}$ & $0.93 \pm 0.02^{\mathrm{a}}$ & $0.29 \pm 0.01^{\mathrm{a}}$ & $0.15 \pm 0.01^{\mathrm{a}}$ \\
\hline \multirow[t]{2}{*}{ PDB } & Mycelium & $0.83 \pm 0.02^{\mathrm{d}}$ & $0.24 \pm 0.01^{\mathrm{d}}$ & $0.17 \pm 0.01^{\mathrm{d}}$ & $0.010 \pm 0.001^{\mathrm{c}}$ \\
\hline & Culture medium & $0.95 \pm 0.03^{c}$ & $0.29 \pm 0.02^{c}$ & $0.20 \pm 0.01^{\mathrm{c}}$ & $0.014 \pm 0.002^{\mathrm{bc}}$ \\
\hline iMMN solid & Mycelium & $0.62 \pm 0.03^{\mathrm{e}}$ & $0.17 \pm 0.01^{\mathrm{e}}$ & $0.14 \pm 0.02^{\mathrm{e}}$ & $0.016 \pm 0.001^{\mathrm{b}}$ \\
\hline PDA & Mycelium & $0.59 \pm 0.02^{f}$ & $0.16 \pm 0.01^{\mathrm{e}}$ & $0.14 \pm 0.01^{\mathrm{e}}$ & $0.011 \pm 0.001^{\mathrm{c}}$ \\
\hline \multirow[t]{2}{*}{$p$-value $(\mathrm{n}=54)$} & Homoscedasticity $^{1}$ & 0.003 & $<0.001$ & $<0.001$ & $<0.001$ \\
\hline & 1-way ANOVA 2 & $<0.001$ & $<0.001$ & $<0.001$ & $<0.001$ \\
\hline
\end{tabular}

\footnotetext{
1 Homoscedasticity among culture components was tested by the Levene test: homoscedasticity, $p>0.05$; heteroscedasticity, $p<0.05$.

$2 p<0.05$ indicates that the mean value of at least one component differs from the others (in this case, multiple comparison tests were performed). For each culture component, means within a column with different letters differ significantly $(p<0.05)$.
}

released to the culture medium; they are kept in the mycelium. Without exception, the mycelia and the culture media of $S$. bellinii gave better results than the same components of $P$. eryngii.

In coherence with the observed for the fruiting bodies, the results obtained with $P$. eryngii mycelia were better than the reported previously, except for DPPH scavenging activity (Reis et al., 2012).

In general, the detected antioxidant activity represents an important added-value, despite the weaker performance of the mycelium and culture medium extracts when compared with the DPPH scavenging activity ( $E_{50}$ values ranging from 0.8 to $3 \mathrm{mg} /$ $\mathrm{mL})$ and reducing power $\left(\mathrm{EC}_{50}=0.5 \mathrm{mg} / \mathrm{mL}\right)$ obtained in polysaccharide fractions of P. eryngii (Li \& Shah, 2014; Ma et al., 2016; Zhang et al., 2016). However, it should be reminded that the results presented herein were obtained with raw extracts, not with purified fractions.

Due to the lack of studies with the mycelia of S. bellinii, no comparisons could be performed.

\subsection{Anti-inflammatory activity}

Macrophages, the main components of the innate immune system, have essential regulation functions in several immunopathological conditions during the inflammatory process (Yoon et al., 2009; Yuan, Wahlqvist, He, Yang, \& Li, 2006). However, the overproduction of inflammatory mediators in the course of uncontrolled inflammation processes might cause adverse consequences in the pathogenesis of many inflammatory diseases such as cancer, diabetes and cardiovascular disease (Yuan et al., 2006). Endotoxin lipopolysaccharide (LPS) is able to induce the production of mediators like nitric oxide (NO), pro-inflammatory cytokines (besides inhibiting anti-inflammatory cytokines) and tumor necrosis factor in macrophages. Thereby, macrophages stimulated by LPS have been widely used for anti-inflammatory activities evaluation in vitro (García-Lafuente, Guillamón, Villares, Rostagno, \& Martínez, 2009). In addition, due to the reproducible response of RAW264.7 macrophages to LPS, this cell line has been widely used for inflammatory research (Huang \& Ho, 2010).

Accordingly, the anti-inflammatory activity was evaluated using a LPS-stimulated RAW264.7 cell line (Table 3). The highest activity was measured in the methanolic extracts prepared from the fruiting bodies of $S$. bellinii $\left(\mathrm{EC}_{50}=90 \mu \mathrm{g} / \mathrm{mL}\right.$ extract). The extracts of $P$. eryngii were also able to suppress NO production, but in less extent $\left(\mathrm{EC}_{50}=223 \mu \mathrm{g} / \mathrm{mL}\right.$ extract). However, these results were better than those obtained in previous assays (Taofiq et al., 2015).

Regarding the evaluated culture components, some interesting results were obtained, especially for the mycelia of $P$. eryngii grown in solid media, which showed higher anti-inflammatory activity $\left(\mathrm{EC}_{50}=184-189 \mu \mathrm{g} / \mathrm{mL}\right.$ extract$)$ than the corresponding fruiting bodies, highlighting their possible use in anti-inflammatory applications.

Moro et al. (2012) found that the phenolic compounds of the fruiting bodies might contribute to their anti-inflammatory activities, inducing inhibition of NO production and iNOS expression in LPS-activated RAW264.7 cells. However, the anti-inflammatory activity of the mycelia of $S$. bellinii was not maintained in neither of the culture components, indicating that the anti-inflammatory effects of the extracts appeared to be related with other components besides ergosterol and phenolic acids. Considering the chemical composition of mushroom, this activity might be related with compounds such as heteropolysaccharides (Lima et al., 2016), triterpenes (Choi et al., 2014) or carotenoids (Moro et al., 2012).

\subsection{Cytotoxicity}

The results for the anti-proliferative activity assayed in four human tumor cell lines (MCF-7, NCI-H460, HeLa and HepG2) and a porcine liver primary cell line (PLP2) are shown in Table 3.

The extracts prepared from the fruiting bodies of wild $S$. bellinii samples showed higher activity against MCF7 $\left(\mathrm{GI}_{50}=70 \mu \mathrm{g} / \mathrm{mL}\right.$ extract), NCI-H460 (GI ${ }_{50}=65 \mu \mathrm{g} / \mathrm{mL}$ extract $)$ and HepG2 $\left(\mathrm{GI}_{50}=68 \mu \mathrm{g} / \mathrm{mL}\right.$ extract $)$. However, the same extracts could not inhibit the HeLa cell line (up to the maximum assayed concentration: $400 \mu \mathrm{g} / \mathrm{mL}$ extract). On the other hand, the extracts from the fruiting bodies of wild $P$. eryngii samples had a similar behavior in all cell lines $\left(\mathrm{GI}_{50}\right.$ values varying from $224 \mu \mathrm{g} / \mathrm{mL}$ extract in HepG2 to $246 \mu \mathrm{g} / \mathrm{mL}$ extract in MCF7). The anti-proliferative activity of $P$. eryngii extracts (specifically, its polysaccharides fraction) was previously reported in HepG2, where it induced apoptosis, cell cycle 
Table 3

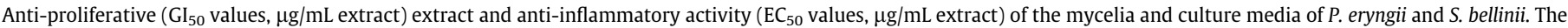
values corresponding to the fruiting body of both mushrooms (wild samples) are also presented. Values are given as mean \pm standard deviation.

\begin{tabular}{|c|c|c|c|c|c|c|c|}
\hline & & MCF-7 & $\mathrm{NCI}-\mathrm{H} 460$ & HeLa & HepG2 & PLP2 & RAW264.7 \\
\hline \multicolumn{8}{|l|}{ Pleurotus eryngii } \\
\hline Fruiting body (wild) & & $246 \pm 6$ & $237 \pm 10$ & $243 \pm 10$ & $224 \pm 12$ & $>400$ & $223 \pm 9$ \\
\hline \multirow[t]{2}{*}{ iMMN liquid } & Mycelium & $242 \pm 7^{c}$ & $275 \pm 12 c^{d}$ & $265 \pm 4^{\mathrm{d}}$ & $280 \pm 3^{c}$ & $>400$ & $>400^{\mathrm{a}}$ \\
\hline & Culture medium & $>400^{\mathrm{a}}$ & $>400^{\mathrm{a}}$ & $>400^{\mathrm{a}}$ & $>400^{\mathrm{a}}$ & $>400$ & $>400^{\mathrm{a}}$ \\
\hline \multirow[t]{2}{*}{ PDB } & Mycelium & $270 \pm 15^{\mathrm{b}}$ & $268 \pm 5^{d}$ & $280 \pm 1^{c}$ & $224 \pm 11^{\mathrm{d}}$ & $>400$ & $308 \pm 10^{\mathrm{b}}$ \\
\hline & Culture medium & $>400^{\mathrm{a}}$ & $>400^{\mathrm{a}}$ & $>400^{\mathrm{a}}$ & $>400^{\mathrm{a}}$ & $>400$ & $>400^{\mathrm{a}}$ \\
\hline iMMN solid & Mycelium & $169 \pm 12^{\mathrm{d}}$ & $363 \pm 13^{b}$ & $302 \pm 9^{b}$ & $314 \pm 2^{\mathrm{b}}$ & $>400$ & $189 \pm 7^{c}$ \\
\hline PDA & Mycelium & $173 \pm 8^{d}$ & $285 \pm 10^{c}$ & $267 \pm 20^{d}$ & $140 \pm 6^{\mathrm{e}}$ & $>400$ & $184 \pm 6^{c}$ \\
\hline \multirow[t]{2}{*}{$p$-value $(\mathrm{n}=54)$} & Homoscedasticity & $<0.001$ & $<0.001$ & $<0.001$ & $<0.001$ & - & $<0.001$ \\
\hline & 1-way ANOVA & $<0.001$ & $<0.001$ & $<0.001$ & $<0.001$ & - & $<0.001$ \\
\hline \multicolumn{8}{|l|}{ Suillus bellinii } \\
\hline Fruiting body (wild) & & $70 \pm 2$ & $65 \pm 3$ & $>400$ & $68 \pm 3$ & $215 \pm 38$ & $90 \pm 2$ \\
\hline \multirow[t]{2}{*}{ iMMN liquid } & Mycelium & $>400^{\mathrm{a}}$ & $>400^{\mathrm{a}}$ & $>400$ & $>400^{\mathrm{a}}$ & $>400$ & $>400$ \\
\hline & Culture medium & $>400^{\mathrm{a}}$ & $>400^{\mathrm{a}}$ & $>400$ & $>400^{\mathrm{a}}$ & $>400$ & $>400$ \\
\hline \multirow[t]{2}{*}{ PDB } & Mycelium & $300 \pm 7^{b}$ & $279 \pm 2^{b}$ & $>400$ & $226 \pm 5^{b}$ & $>400$ & $>400$ \\
\hline & Culture medium & $>400^{\mathrm{a}}$ & $>400^{\mathrm{a}}$ & $>400$ & $>400^{\mathrm{a}}$ & $>400$ & $>400$ \\
\hline iMMN solid & Mycelium & $>400^{\mathrm{a}}$ & $>400^{\mathrm{a}}$ & $>400$ & $>400^{\mathrm{a}}$ & $>400$ & $>400$ \\
\hline PDA & Mycelium & $289 \pm 11^{\mathrm{c}}$ & $257 \pm 2^{\mathrm{c}}$ & $>400$ & $206 \pm 11^{c}$ & $>400$ & $>400$ \\
\hline \multirow[t]{2}{*}{$p$-value $(\mathrm{n}=54)$} & Homoscedasticity & $<0.001$ & $<0.001$ & - & $<0.001$ & - & - \\
\hline & 1-way ANOVA & $<0.001$ & $<0.001$ & - & $<0.001$ & - & - \\
\hline
\end{tabular}

${ }^{1}$ Homoscedasticity among culture components was tested by the Levene test: homoscedasticity, $\mathrm{p}>0.05$; heteroscedasticity, $\mathrm{p}<0.05$.

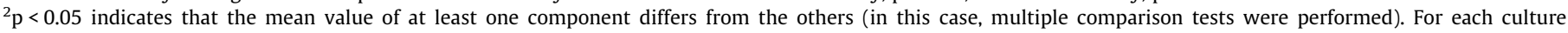
component, means within a column with different letters differ significantly $(p<0.05)$.

arrest at the S-phase and intracellular production of reactive oxygen species (Yang et al., 2013). Besides its in vitro anti-tumoral activity, $P$. eryngii was previously reported as being active against mice renal cancer in vivo (Yang et al., 2013). Despite their generally lower activity against tumor cell lines, the extracts from $P$. eryngii did not exhibit a toxic effect on the primary cell line, contrarily with the observed for $S$. bellinii fruiting bodies.

Interestingly, none of the assayed culture components inhibit the growth of PLP2 cell line, which constitutes a good indicator of the lack of toxicity of the mycelia and culture media of both mushroom species in non-tumor cell lines.

Concerning the tumor cell lines, the mycelia of P. eryngii showed similar cytotoxicity to the fruiting bodies. In fact, the measured activity was often higher than the observed for the fruiting bodies. In some cases, such as the mycelium grown in PDA medium, the $\mathrm{GI}_{50}$ values are comparable to those obtained with purified polysaccharide fractions (Ma et al., 2014, 2016; Ren et al., 2016), which represents a very interesting result.

On the other hand, the mycelia of $S$. bellinii showed significantly lower anti-proliferative activity, when compared to the fruiting bodies.

The culture media did not show any anti-proliferative activity (up to the maximum assayed concentrations) in both mushroom species

\section{Conclusion}

This study was initially designed to evaluate the mycelia of $P$. eryngii and $S$. bellinii, as well as their culture media, as potential alternative sources of bioactive compounds or as ingredients to be used in applications with antioxidant, anti-inflammatory or cytotoxic activities. In general, $S$. bellinii mycelia showed higher contents of ergosterol and phenolic compounds, which were also more abundant in the fruiting body of this species. Likewise, the antioxidant activity was also higher among the $S$. bellinii components. However, these extracts did not show anti-inflammatory activity up to the maximum assayed concentrations, contrarily to the observed for the mycelia of $P$. eryngii. Furthermore, the latter component showed a cytotoxicity similar (and often superior) to its fruiting bodies, in opposition to $S$. bellinii, whose mycelia showed a significant loss of anti-proliferative activity. In general, each culture component showed differentiated activity, which should be considered together with the growth rate and biomass yielded for each mushroom.

\section{Acknowledgments}

The authors are grateful to the Foundation for Science and Technology (FCT, Portugal) and FEDER under Programe PT2020 for financial support to CIMO (UID/AGR/00690/2013), LSRE (Project UID/EQU/50020/2013), J.C.M. Barreira (BPD/72802/2010), L. Barros (SFRH/BPD/107855/2015), and R.C. Calhelha (SFRH/BPD/ BPD/68344/2010) grants.

\section{References}

Abreu, R. M. V., Ferreira, I. C. F. R., Calhelha, R. C., Lima, R. T., Vasconcelos, M. H., Adega, F., ... Queiroz, M. J. R. P. (2011). Anti-hepatocellular carcinoma activity using human HepG2 cells and hepatotoxicity of 6-substituted methyl 3aminothieno [3,2-b] pyridine-2-carboxylate derivatives: In vitro evaluation, cell cycle analysis and QSAR studies. European Journal of Medicinal Chemistry, 46, 5800-5806.

Barreira, J. C. M., Oliveira, M. B. P. P., \& Ferreira, I. C. F. R. (2014). Development of a novel methodology for the analysis of ergosterol in mushrooms. Food Analytical Methods, 7, 217-223.

Chen, J. J., Mao, D., Yong, Y. Y., Li, J. L., Wei, H., \& Lu, L. (2012). Hepatoprotective and hypolipidemic effects of water-soluble polysaccharidic extract of Pleurotus eryngii. Food Chemistry, 130, 687-694.

Chen, J. J., Yong, Y. Y., Xia, X., Wang, Z. L., Liang, Y. X., Zhang, S. Z., et al. (2014). The excreted polysaccharide of Pleurotus eryngii inhibits the foam-cell formation via down-regulation of CD36. Carbohydrate Polymers, 112, 16-23.

Choi, S., Nguyen, V. T., Tae, N., Lee, S., Ryoo, S., Min, B.-S., et al. (2014). Antiinflammatory and heme oxygenase-1 inducing activities of lanostane triterpenes isolated from mushroom Ganoderma lucidum in RAW264.7 cells. Toxicology and Applied Pharmacology, 280, 434-442.

Dulger, B., Hacioglu, N., \& Suerdem, T.B. (2006). Evaluation of antimicrobial activity of the macrofungus Suillus bellinii. In Plant, fungal and habitat diversity investigation and conservation, Proceedings of IV BBC - Sofia, pp. 670-673.

Ferreira, I. C. F. R., Barros, L., \& Abreu, R. M. V. (2009). Antioxidant in wild mushrooms. Current Medicinal Chemistry, 16, 1543-1560.

Franco, A. R. \& Castro, P. M. L. (2015). Inoculation of Pinus pinea seedlings with Pisolithus tinctorius and Suillus bellinii promotes plant growth in benfluralin contaminated soil. Plant and Soil, 386, 113-123.

Gan, D., Ma, L. P., Jiang, C. X., Wang, M. C., \& Zeng, X. X. (2012). Medium optimization and potential hepatoprotective effect of mycelial polysaccharides from Pholiota dinghuensis Bi against carbon tetrachloride-induced acute liver injury in mice. Food and Chemical Toxicology, 50, 681-2688. 
García-Lafuente, A., Guillamón, E., Villares, A., Rostagno, M. A., \& Martínez, J. A. (2009). Flavonoids as anti-inflammatory agents: Implications in cancer and cardiovascular disease. Inflammation Research, 58, 537-552.

Guedes De Pinho, P., Ribeiro, B., Gonçalves, R. F., Baptista, P., Valentão, P., Seabra, R. M., et al. (2008). Correlation between the pattern volatiles and the overall aroma of wild edible mushrooms. Journal of Agricultural and Food Chemistry, 56, 1704-1712.

Guimarães, R., Barros, L., Dueñas, M., Calhelha, R. C., Carvalho, A. M., Santos-Buelga, C., et al. (2013). Nutrients, phytochemicals and bioactivity of wild Roman chamomile: A comparison between the herb and its preparations. Food Chemistry, 136, 718-725.

Heleno, S. A., Barros, L., Sousa, M. J., Martins, A., \& Ferreira, I. C. F. R. (2010). Tocopherols composition of Portuguese wild mushrooms with antioxidant capacity. Food Chemistry, 119, 1443-1450.

Heleno, S. A., Martins, A., Queiroz, M. J. R. P., \& Ferreira, I. C. F. R. (2015). Bioactivity of phenolic acids: Metabolites versus parent compounds: A review. Food Chemistry, 173, 501-513.

Huang, Y. S., \& Ho, S. C. (2010). Polymethoxy flavones are responsible for the antiinflammatory activity of citrus fruit peel. Food Chemistry, 119, 868-873.

Izumi, H., Elfstrand, M., \& Fransson, P. (2013). Suillus mycelia under elevated atmospheric $\mathrm{CO}_{2}$ support increased bacterial communities and scarce nifH gene activity in contrast to Hebeloma mycelia. Mycorrhiza, 23, 155-165.

Jayakumar, T., Sakthivel, M., Thomas, P. A., \& Geraldine, P. (2008). Pleurotus ostreatus, an oyster mushroom, decreases the oxidative stress induced by carbon tetrachloride in rat kidneys, heart and brain. Chemico-Biological Interactions, 176, 108-120.

Kalogeropoulos, N., Yanni, A. E., Koutrotsios, G., \& Aloupi, M. (2013). Bioactive microconstituents and antioxidant properties of wild edible mushrooms from the island of Lesvos, Greece. Food and Chemical Toxicology, 55, 378-385.

Li, S., \& Shah, N. P. (2014). Antioxidant and antibacterial activities of sulphated polysaccharides from Pleurotus eryngii and Streptococcus thermophilus ASCC 1275. Food Chemistry, 165, 262-270.

Lima, A. T. M., Santos, M. N., de Souza, L. A. R., Pinheiro, T. S., Paiva, A. A. O., Dore, C. M. P. G., et al. (2016). Chemical characteristics of a heteropolysaccharide from Tylopilus ballouii mushroom and its antioxidant and anti-inflammatory activities. Carbohydrate Polymers, 144, 400-409.

Lin, J. T., Liu, C. W., Chen, Y. C., Hu, C. C., Juang, L. D., Shiesh, C. C., et al. (2014). Chemical composition, antioxidant and anti-inflammatory properties for ethanolic extracts from Pleurotus eryngii fruiting bodies harvested at different time. LWT - Food Science and Technology, 55, 374-382.

Ma, G., Yang, W., Fang, Y., Ma, N., Pei, F., Zhao, L., et al. (2016). Antioxidant and cytotoxicites of Pleurotus eryngii residue polysaccharides obtained by ultrafiltration. LWT - Food Science and Technology, 73, 108-116.

Ma, G. X., Yang, W. J., Mariga, A. M., Fang, Y., Ma, N., Pei, F., et al. (2014). Purification, characterization and antitumor activity of polysaccharides from Pleurotus eryngii residue. Carbohydrate Polymers, 114, 297-305.

Marx, D. H. (1969). The influence of ectotrophic fungi on the resistance of pine roots to pathogenic infections. I. Antagonism of mycorrhizal fungi to root pathogenic fungi and soil bacteria. Phytopathology, 59, 153163.
Mishra, K. K., Pal, R. S., Arunkumar, R., Chandrashekara, C., Jain, S. K., \& Bhatt, J. C. (2013). Antioxidant properties of different edible mushroom species and increased bioconversion efficiency of Pleurotus eryngii using locally available casing materials. Food Chemistry, 138, 1557-1563.

Moro, C., Palacios, I., Lozano, M., D’Arrigo, M., Guillamón, E., \& Villares, A. (2012). Anti-inflammatory activity of methanolic extracts from edible mushrooms in LPS activated RAW 264.7 macrophages. Food Chemistry, 130, 350-355.

Reis, F. S., Barros, L., Sousa, M. J., Martins, A., \& Ferreira, I. C. F. R. (2014). Analytical methods applied to the chemical characterization and antioxidant properties of three wild edible mushroom species from northeastern Portugal. Food Analytical Methods, 7, 645-652.

Reis, F. S., Martins, A., Barros, L., \& Ferreira, I. C. F. R. (2012). Antioxidant properties and phenolic profile of the most widely appreciated cultivated mushrooms: A comparative study between in vivo and in vitro samples. Food and Chemical Toxicology, 50, 1201-1207.

Ren, D., Wang, N., Guo, J., Yuan, L., \& Yang, X. (2016). Chemical characterization of Pleurotus eryngii polysaccharide and its tumor-inhibitory effects against human hepatoblastoma HepG-2 cells. Carbohydrate Polymers, 138, 123-133.

Ribeiro, B., Rangel, J., Valentão, P., Baptista, P., Seabra, R. M., \& Andrade, P. B. (2006) Contents of carboxylic acids and two phenolics and antioxidant activity of dried Portuguese wild edible mushrooms. Journal of Agricultural and Food Chemistry, 54, 8530-8537.

Shi, X., Zhao, Y., Jiao, Y., Shi, T., \& Yang, X. (2013). ROS-dependent mitochondria molecular mechanisms underlying antitumor activity of Pleurotus abalonus acidic polysaccharides in human breast cancer MCF-7 cells. PLOS ONE, 8, e64266.

Souza, A., Corrêa, R. C. G. Barros, L. Calhelha, R. C. Santos-Buelga, C., Peralta, R. M. et al. (2015). Phytochemicals and bioactive properties of Ilex paraguariensis: An in-vitro comparative study between the whole plant, leaves and stems. Food Research International, 78, 286-294.

Taofiq, O., Calhelha, R. C., Heleno, S., Barros, L., Martins, A., Santos-Buelga, C., ... Ferreira, I. C. F. R. (2015). The contribution of phenolic acids to the antiinflammatory activity of mushrooms: Screening in phenolic extracts, individual parent molecules and synthesized glucuronated and methylated derivatives. Food Research International, 76, 821-827.

Yang, Z. Y., Xu, J., Fu, Q., Fu, X. L., Shu, T., Bi, Y. P., et al. (2013). Antitumor activity of a polysaccharide from Pleurotus eryngii on mice bearing renal cancer. Carbohydrate Polymers, 95, 615-620.

Yoon, W. J., Ham, Y. M., Kim, S. S., Yoo, B. S., Moon, J. Y., Baik, J. S., et al. (2009). Suppression of pro-inflammatory cytokines, iNOS, and COX-2 expression by brown algae Sargassum micracanthum in RAW 264.7 macrophages. EurAsian Journal of BioSciences, 3, 130-143.

Yuan, G., Wahlqvist, M. L., He, G., Yang, M., \& Li, D. (2006). Natural products and anti-inflammatory activity. Asia Pacific Journal of Clinical Nutrition, 15, 143-152.

Zhang, C., Li, S., Zhang, J., Hu, C., Che, G., Zhou, M., et al. (2016). Antioxidant and hepatoprotective activities of intracellular polysaccharide from Pleurotus eryngii SI-04. International Journal of Biological Macromolecules, 91, 568-577. 